\title{
Understanding the Effects of Transferring In Statics Credit on Performance in Future Mechanics Courses
}

\section{Dr. Jacob R Grohs, Virginia Tech}

Jacob Grohs is an Assistant Professor in Engineering Education at Virginia Tech with Affiliate Faculty status in Biomedical Engineering and Mechanics and the Learning Sciences and Technologies at Virginia Tech. He holds degrees in Engineering Mechanics (BS, MS) and in Educational Psychology (MAEd, $\mathrm{PhD})$.

\section{Ms. Michelle M Soledad, Virginia Tech, Ateneo de Davao University}

Michelle Soledad is a doctoral student and graduate research assistant in the Department of Engineering Education at Virginia Polytechnic Institute and State University. Her research interests include faculty motivation and development towards supporting student success. Ms. Soledad has bachelor's and master's degrees in Electrical Engineering from the Ateneo de Davao University in Davao City, Philippines, where she continues to be a faculty member of the Electrical Engineering Department. She also served as Department Chair and was a member of the University Research Council before pursuing doctoral studies at Virginia Tech. Prior to joining the Ateneo de Davao University roster of faculty in 2008, Ms. Soledad was a Senior Team Lead for Accenture, where she worked on and managed systems maintenance and enhancement projects.

\section{Dr. David B Knight, Virginia Tech Department of Engineering Education}

David Knight is an Assistant Professor in the Department of Engineering Education and affiliate faculty with the Higher Education Program, Center for Human-Computer Interaction, and Human-Centered Design Program. His research focuses on student learning outcomes in undergraduate engineering, learning analytics approaches to improve educational practices and policies, interdisciplinary teaching and learning, organizational change in colleges and universities, and international issues in higher education.

\section{Prof. Scott W Case, Virginia Tech}

Scott W. Case is a Professor of Engineering Mechanics at Virginia Tech. He has served as associate department head of Engineering Science and Mechanics and as Interim Associate Dean for Academic Affairs within the College of Engineering. 


\section{Understanding the Effects of Transferring In Statics Credit on Performance in Future Mechanics Courses}

\section{Introduction}

The demand for graduating additional engineers who come from diverse backgrounds has increased over the past several years. These calls have been accompanied by the emergence of a global society beset with complex, interdisciplinary problems that are best addressed by innovative technology-based solutions. ${ }^{1}$ Thus, it has become imperative for engineering institutions to formulate strategies towards recruiting and retaining students with diverse backgrounds who will assume critical roles in a global workplace. ${ }^{2}$ One strategy that has received recent emphasis is an approach that bolsters and supports students who choose alternative pathways towards earning undergraduate engineering degrees, such as transfer students from community colleges. ${ }^{3,4}$ Student retention and persistence in engineering programs, however, continue to be a widespread concern, ${ }^{5,6,7,8}$ both for transfer students and for students who follow a more traditional path through a four-year degree-granting institution. Persistence and time-to-degree concerns are a problem within this field, perhaps more so than others, because of the presence of challenging courses in engineering curricula that build upon one another sequentially.

Students have dealt with challenging engineering courses in various ways; one strategy that has been observed is transferring credits. This phenomenon may occur in a number of scenarios, and may be practiced by different groups of students. Student profiles based on transfer behavior may include transitioning from a community college to a 4-year institution (vertical transfer); transferring from one 4-year institution to another (lateral transfer); transferring from one institution to another, but eventually going back to the original institution (swirl); or enrolling concurrently in two institutions (double-dipping). ${ }^{3,9}$ In each of these scenarios, students may choose to transfer credits for courses taken in other institutions into the institution in which they are currently enrolled. This is a critical decision that any engineering student who chooses to transfer credits will need to make, as the latest phase in the evolution of engineering education has given colleges and universities a certain degree of autonomy in designing a broad and holistic engineering curriculum, ${ }^{2}$ leading to a possible lack of course transferability between institutions. $^{3}$

The decision to transfer credits may be influenced by several factors, such as academic advising, institutional transfer policies, and student perceptions regarding course transferability and academic rigor in the receiving institution. Incidentally, perceived weaknesses associated with these factors have also been identified as barriers to transfer student success in engineering degrees. ${ }^{5}$ The generation of information that will help facilitate academic advising and provide input to a students' personal decision-making process regarding transferring credits will prove to be valuable to student retention and persistence, and may contribute towards breaking down some barriers to transfer student success in engineering degrees.

\section{Focus of this Investigation: Required Mechanics Courses}


Statics is a course that students often choose to transfer previously-earned credits into a receiving institution; this course is foundational and required in most engineering programs ${ }^{10,11}$ and prerequisite to other Engineering Mechanics (e.g. Mechanics of Deformable Bodies/Strength of Materials, Dynamics) and discipline-specific (e.g. Mechanical Design, Theory of Structures) courses. However, several characteristics often make Statics a major barrier for student persistence and success. The course contains conceptually challenging material ${ }^{10,11}$ and it is usually taken along with other concept- and calculations-heavy courses in the curricula, such as Physics and Multivariable Calculus. ${ }^{10,11}$ These courses are typically taken during a student's second year in the engineering program - a period that has been associated with academic difficulties. ${ }^{12,13}$ Furthermore, a steady growth in enrollment in engineering programs coupled with slower growth in faculty numbers has brought about the necessity of teaching foundational courses taken by multiple disciplines in large section sizes, a situation that poses a number of challenges for both instructors and the students. Instructors of large classes may find it difficult to provide individualized, timely, and targeted feedback, and may be prone to being disengaged from the class; these challenges may result in teaching strategies that are detrimental to student learning. ${ }^{17}$ It is therefore important for a student to be able to self-assess readiness to take courses dependent upon Statics and make an informed decision when transferring credits earned from a previous institution.

Informed by the discussion above, we believe that Statics represents a particularly critical course affecting students' progress towards an engineering degree. Mindful of this, we are interested in how and when students take their mechanics courses and the effects of different course planning strategies on academic performance. This study uses transcript data from across 5 years at a large public research institution to examine how strategies to transfer credits in from other institutions affect performance on subsequent courses that require a certain level of understanding in Statics, specifically Mechanics of Deformable Bodies/Strength of Materials and Dynamics.

\section{The Dataset and Relevant Institution Specific Context}

This dataset is built from Institutional Research transcript data at a single institution that includes a population of students who received credit for all instances of Statics, Mechanics of Deformable Bodies/Strength of Materials, or Dynamics from students over 5 years. At this institution, the Statics course serves as a pre-requisite to the other two courses; most engineering majors are required to take at least two of the three courses. A transcript "instance" in the dataset includes traditional completed attempts associated with the course (A-F), approved transferred credit from another institution (T), or a course withdrawal (W) which allows students who have completed a significant portion of a course to drop the course late with no penalty to their GPA (Course withdrawals are limited to 3 courses per student for the entire academic life of the student in the institution). The data are de-identified but linked so that any instances for the same student can be combined together. The dataset contains almost 7900 students who have attempted Statics within the time window (2009-2014), not including those students who dropped the course without grade penalty (within the first seven weeks of the semester). In addition to the course attempt data, each instance also includes the student's declared major at the time of the attempt, if/what degrees have been awarded for the student, and whether the individual entered the university as either a transfer or a freshman admit student. Transfer student status includes any student who has previously attended another college or university 
before coming to the new institution, and may include vertical or lateral transfers. It is important to note that first-time admit students begin their college career at a particular institution but may, while still working on a degree from that institution, choose to take courses at another institution and transfer courses back to the degree-granting institution (double-dipping). In the case of engineering mechanics courses, transfer students may bring in some or all mechanics course credit because of earned Associate's degrees, preparation curricula for entrance into a four-year engineering program, or transfer from one school's undergraduate engineering program to another. Reasons to transfer credits through double-dipping, on the other hand, vary significantly; this strategy can be used to catch up or get ahead in one's curriculum, to circumvent a difficult course by taking it somewhere it might be "easier." Thus, this data set allows us to investigate not only the effect of transferring any Statics credit in but also to tag specific profiles of transfer behavior (e.g., students with a failing first attempt who then go take Statics at another institution).

\section{Results and Discussion}

Data coming from Institutional Research used study codes to allow for linking different course instances to a single individual but was not structured with that end in mind (i.e., individual rows represented different course instances and needed to be collated). A program written in Mathematica structured the data appropriately in a form that SPSS could use in order to run basic descriptive statistics and hypothesis testing. Table 1 shows a crosstabulation of course grades for the first instance that a student took Statics (that was recorded on a student transcript) by freshman (i.e., traditional pathway) or transfer admit status. Course grades are collapsed into typical letter grades (A-F) in addition to $\mathrm{W}$ (course withdrawal) and $\mathrm{T}$ (transfer credit representing a sufficiently high grade from an approved institution).

Table 1. Course grade on first Statics attempt for traditional admit and transfer admit students

\begin{tabular}{c|c|c|c|c|c|c|c|c} 
& \multicolumn{7}{|c|}{ Course Grade on First Statics Attempt } & \multirow{2}{*}{ Totals } \\
\hline Admitted as Freshman & 696 & 1181 & 431 & 655 & 1562 & 1413 & 1008 & 6946 \\
\hline Admitted as Transfer Student & 638 & 60 & 34 & 38 & 71 & 55 & 40 & 936 \\
\hline Total & 1334 & 1241 & 465 & 693 & 1633 & 1468 & 1048 & 7882
\end{tabular}

Findings from Table 1 enabled us to better understand the data and to target further investigation. Of particular note in Table 1, we found:

- Of 7882 individuals with instances of Statics on their transcripts, 1334 (17\%) of those students have successful transfer credit for Statics.

- Of 1334 students with successful transfer credit (T) for Statics, 696 (52\%) were admitted to the institution as Freshman and thus represent an unexpectedly large group that is working around the expected path. These 696 students comprise $10 \%$ of all students who entered the institution through the traditional path, meaning that $10 \%$ of students elect to take this course at a different institution (and thus pay additional tuition elsewhere). Of course, looking only at transcript data, we cannot determine the reason for such behavior (e.g., to get ahead, to circumvent a difficult course).

- Of 936 transfer students, 638 (68\%) are carrying in approved Statics credit. 
- A large group (both freshman admit and transfer students) is unsuccessful on their first attempt in Statics. Of students receiving a course grade at the institution (i.e., A-F or W), 2399 of 6548 (37\%) earn a W, F, or D which do not meet the typical C- requirement in Statics required by most disciplines. To further investigate this issue, Table 2 describes a similar crosstabulation as Table 1, but presents the number of instances that Statics appears on a student's record (which corresponds to the number of times a student attempted the course). Please note that the minor discrepancy in total $\mathrm{N}$ between the tables is a result of ignoring some grades (e.g., audit as a course grade) in Table 1 but still counting them to show in Table 2 .

Table 2. Instances of Statics on transcripts for traditional admit and transfer admit students

\begin{tabular}{|c|c|c|c|c|c|}
\hline & \multicolumn{4}{|c|}{ \# of Statics Instances } & \multirow[b]{2}{*}{ Totals } \\
\hline & 1 & 2 & 3 & 4 & \\
\hline Admitted as Freshman & 5578 & 1185 & 170 & 25 & 6958 \\
\hline Admitted as Transfer Student & 848 & 86 & 5 & 0 & 939 \\
\hline Total & 6426 & 1271 & 175 & 25 & 7897 \\
\hline
\end{tabular}

Considering Tables 1 and 2 together, these data show evidence of student departure. This is evidenced by the discrepancy between the 2399 students who did not earn the requisite Crequired for most disciplines (thus indicating a repeat instance would be needed to progress) and the 1471 students that re-attempted Statics for a total of two, three, or four attempts. On one hand, this is not unexpected - Statics is a difficult course and positioned such that we anticipate it to be a barrier to persistence in engineering. However, because it is often taken in the second year or later, and students may attempt it multiple times, and because reattempting does not guarantee success, it is a troublingly late time to depart from engineering with much tuition and time already spent. This apparent departure point (discrepancy between unsuccessful first attempts and number of reattempts) can be more rigorously investigated in the future with actual data on the declared major at time of Statics instance vs degree earned later.

Tables 3 and 4 begin the investigation of how transferring in credit for Statics might relate to grades in the follow-on courses of Mechanics of Deformable Bodies/Strength of Materials and Dynamics. In each case, crosstabulations are shown to see how course grades differed among first attempts from groups who did or did not transfer in Statics credit (note: transferring in Statics credit was done by both transfer students and traditional freshman admit students through a workaround as discussed earlier).

Table 3. Course Grade on First Attempt in Mechanics of Deformable Bodies for groups transferring/not transferring Statics credit

\begin{tabular}{c|c|c|c|c|c|c|c|c} 
& \multicolumn{6}{|c}{ Course Grade on First Deforms Instance/Attempt } & \multirow{2}{*}{} \\
& $\mathbf{T}$ & $\mathbf{W}$ & $\mathbf{F}$ & $\mathbf{D}$ 's & C's & B's & A's & Totals \\
\hline No Statics transfer credit & 289 & 360 & 238 & 427 & 1089 & 1104 & 675 & 4182 \\
\hline Statics transfer credit & 654 & 77 & 44 & 65 & 124 & 88 & 32 & 1084 \\
\hline Total & 943 & 437 & 282 & 492 & 1213 & 1192 & 707 & 5266
\end{tabular}


Table 4. Course grade on first attempt in Dynamics for groups transferring/not transferring Statics Credit

\begin{tabular}{c|c|c|c|c|c|c|c|c} 
& \multicolumn{6}{|c|}{ Course Grade on First Dynamics } & \\
& $\mathbf{T}$ & $\mathbf{W}$ & $\mathbf{F}$ & $\mathbf{D}$ 's & $\mathbf{C}$ 's & B's & A's & Totals \\
\hline No Statics transfer credit & 448 & 439 & 178 & 365 & 887 & 891 & 512 & 3720 \\
\hline Statics transfer credit & 743 & 58 & 31 & 50 & 64 & 51 & 23 & 1020 \\
\hline Total & 1191 & 497 & 209 & 415 & 951 & 942 & 535 & 4740
\end{tabular}

A primary purpose of this study was to explore whether transferring in credit for Statics significantly related to course grades in a subsequent course. The majority of students with transfer credit for Statics actually transfer in credit again for subsequent courses (654 of 1084, $60 \%$, students in Mechanics of Deformable Bodies and 743 of 1020, 73\%, in Dynamics). Of these populations transferring additional credits after also transferring Statics, the ratio of freshman admit student to transfer student admit is 42\%/58\% of 654 in Deforms and 43\%:57\% of 743 in Dynamics. Such a proportionally high number of students transferring credit for multiple courses limits the interpretability of hypothesis testing between the two groups because independent samples t-tests can only be done with numerical A-F grades. That is, to run the ttest, course withdrawal grades were assumed to be F's and transfer credit ( $T$ ) was removed from analysis since any numerical assumptions for $\mathrm{T}$ grades could be problematic (e.g., all $\mathrm{T}$ grades as C's). Table 5 shows the results of such independent samples t-tests where statistical significance was found between the groups leading us to reject the null hypothesis that transferring in statics credit has no effect on performance in subsequent courses. That is, for both Mechanics of Deformable Bodies and Dynamics, the groups that did not transfer statics credit had a statistically significant higher mean than the groups that did transfer statics credit with Cohen's $d$ values indicating a moderate effect size. Cohen's $d$ was used to examine effect sizes using the following general guidelines for interpretation: if $d=0.20$, small effect; if $d=0.50$, medium effect; and if $d=0.80$, large effect. ${ }^{18}$ Though this finding is meaningful, the high rate or repeated transfers (T credit) on two or three of the mechanics courses suggests that to investigate any relationships transferring mechanics credit has on future performance should focus on obtaining transcript data for the follow-on courses for the trio of engineering mechanics courses (e.g., Theory of Structures for Civil Engineering, Thin-walled Structures for Aerospace and Ocean Engineering). Another concern in interpreting Table 5 involves how we might control for student ability differences in transferring/not transferring groups (e.g., are students who double-dip to avoid challenging courses weaker students on average). An initial investigation using student cumulative GPA at the time of the Statics instance does not suggest meaningfully large differences between the groups. A more rigorous investigation could use pre-college characteristics (e.g., SAT math scores) but that information is not a part of our current dataset.

Table 5. Independent samples t-test comparing performance in Mechanics of Deformable Bodies and Dynamics for groups transferring/not transferring Statics credit

\begin{tabular}{|c|c|c|c|c|c|c|c|}
\hline & \multicolumn{3}{|c|}{ No Statics Transfer Credit } & \multicolumn{3}{|c|}{$\underline{\text { Statics Transfer Credit }}$} & \multirow{2}{*}{$\begin{array}{l}\text { Effect Size } \\
\text { Cohen's } d\end{array}$} \\
\hline & $\mathrm{N}$ & M & SD & $\mathrm{N}$ & $\mathrm{M}$ & SD & \\
\hline Defo & 3893 & 2.19 & 1.27 & 430 & 1.62 & 1.27 & $0.45^{* * * *}$ \\
\hline Dynamics & 3272 & 2.09 & 1.31 & 277 & 1.51 & 1.31 & $0.44 * * *$ \\
\hline
\end{tabular}


Note. $* \mathrm{p}<.05 . * * \mathrm{p}<.01 . * * * \mathrm{p}<.001$

\section{Implications and Future Work}

The key findings of this study were:

(1) Statics appears to be a significant barrier to student success and persistence as evidenced by the large number of students unsuccessful on their first attempt and the subsequently smaller number of students who re-attempt (Tables 1 and 2);

(2) Students who transfer course credit for Statics often subsequently transfer credit for Mechanics Bodies and/or Dynamics. Of those students who have transferred Statics credit, both transfer admit students (vertical or lateral transfer), and traditional students who double-dip, transfer at similar rates.

(3) Students who transfer in credit for Statics score lower on average than their peers who do not transfer Statics credit by about half a letter grade ( 0.5 -point difference on a scale of $0-4)$.

These findings carry important implications for both individual students and diverse groups in the institution responsible for advising, enrollment management, transfer policies, and course oversight. At the individual level, students should be made aware of such data to foster reflection and enable students to be more proactive and self-regulating learners. While these findings do not predict specific individual performance, they do highlight possible challenges associated with specific behavior (e.g., double-dipping students) that can help students make informed decisions about their own personal strategies. Future work that would be particularly useful in informing student decision-making should include investigating the rates at which Statics, Mechanics of Deformable Bodies, and/or Dynamics credit are transferred by major, particularly with respect to the espoused level of mechanics required to be successful (e.g., aerospace engineering is considered to be mechanics-heavy).

Though departments may have already addressed policies governing transfer credits from other institutions (e.g., articulation agreements with community colleges), this study can inform such discussions. In particular, departments and advisors could benefit greatly from tools (e.g., concept inventory) which might provide more information about the knowledge and preparation of students transferring Statics credit from another institution. We suggest that such work be done as informal self-assessment rather than formal, required test-to-transfer in an attempt to minimize any systemic bias against transfer students. Such an assessment could be paired with online modules to not only help students to identify any gaps in knowledge but all data could be fed in aggregate to instructors within departments to give a clearer sense of who is in the classroom and the current state of their prior knowledge.

At the institutional level, the finding that a significant number of students, including freshman admit students who double-dip, are transferring credit in for a combinations of Statics, Mechanics of Deformable Bodies, and Dynamics suggest a need for future work to better understand why this occurs and how to more rigorously investigate any relationship between the phenomenon of transferring credits for the Engineering Mechanics cluster itself and student performance in discipline-specific courses that directly require foundational engineering mechanics content. 
As noted, we are unsure why students who were Freshman admits selected the workaround path in such high numbers. Future analyses should determine whether these students share some kind of common characteristic. Perhaps, for example, certain departments encourage their students to take this path if the mechanics courses are less critical for certain majors. If that is the case, we would wonder whether such curricular requirements are necessary for those majors. Alternately, if following a "Transfer" credit approach is deemed easier than taking courses in-residence, we should ensure that students from all socioeconomic backgrounds are able to select this pathway. Each of these "Transfer" courses requires tuition above and beyond students' regular in-semester tuition bills, and ensuring that all students can equally access this path is critical from an inclusive education perspective, especially if it is being recommended by someone within the university.

\section{References}

[1] J. J. Duderstadt, "Engineering for a changing world: A roadmap to the future of engineering practice, research and education," 2008.

[2] National Academy of Engineering, "Educating the Engineer of 2020: Adapting Engineering Education to the New Century," National Academies Press, 2005.

[3] A. M. Ogilvie, D. B. Knight, M. Borrego, A. A. Fuentes, P. A. Nava and V. E. Taylor, "Transfer Student Pathways to Engineering Degrees: A Multi-Institutional Study Based in Texas," in 45th Annual Frontiers in Education (FIE) Conference, El Paso, TX, 2015.

[4] National Research Council, "Enhancing the community college pathway to engineering careers," The National Academies Press, Washington, D.C., 2005.

[5] M. W. Ohland, S. D. Sheppard, G. Lichtenstein, O. Eris, D. Chachra and R. Layton, "Persistence, Engagement and Migration in engineering Programs," Journal of Engineering Education, vol. 97, no. 3, pp. 259-278, 2008.

[6] O. Eris, D. Chachra, H. L. Chen, S. Sheppard, L. Ludlow, C. Rosca, T. Bailey and G. Toye, "Outcomes of a Longitudinal Administration of the Persistence in Engineering Survey," Journal of Engineering Education, vol. 99, no. 4, pp. 371-395, October 2010.

[7] R. M. Marra, "Leaving Engineering: A Multi-Year, Single Institution Study," Journal of Engineering Education, vol. 101, no. 1, pp. 6-27, January 2012.

[8] C. W. Hall, P. J. Kauffman, K. L. Wuensch, W. E. Swart, K. A. DeUrquidi, O. H. Griffin and C. S. Duncan, "Aptitude and Personality Traits in Retention of Engineering Students," Journal of Engineering Education, vol. 104, no. 2, pp. 167-188, April 2015.

[9] E. Shealy, C. E. Brawner, C. Mobley and R. A. Layton, "A Descriptive Study of Engineering Transfer Students at Four Institutions: Comparing Lateral and Vertical Transfer Pathways," in 120th ASEE Annual Conference and Exposition, Atlanta, GA, 2013. 
[10] A. M. Ogilvie, "A Review of the Literature on Transfer Student Pathways to Engineering Degrees," in 121st ASEE Annual Conference and Exposition, Indianapolis, IN, 2014.

[11] Gallogly College of Engineering, The University of Oklahoma, "Degree Requirement Checksheets," 2015. [Online]. Available: http://www.ou.edu/checksheets/engineering.html. [Accessed 28 January 2016].

[12] University of Michigan, "Michigan Engineering," 2015. [Online]. Available: http://www.engin.umich.edu/college/departments/. [Accessed 28 January 2016].

[13] P. S. Steif and A. Dollar, "Reinventing the Teaching of Statics," in Proceedings of the 2004 American Society for Engineering Education Annual Conference \& Exposition, Salt Lake City, Utah, 2004.

[14] P. S. Steif and A. Dollar, "Reinventing the Teaching of Statics," International Journal of Engineering Education, vol. 21, no. 4, pp. 723-706, 2005.

[15] S. M. Lord and J. C. Chen, "Curriculum Design in the Middle Years," in Cambridge Handbook of Engineering Education Research, A. Johri and B. M. Olds, Eds., New York, NY: Cambridge University Press, 2014, pp. 181-199.

[16] M. E. Fox, Scrutinizing Sophomore Slump: An Exploration of Student Behaviors and Institutional Conditions, Los Angeles, CA: University of California - Los Angeles, 2014.

[17] J. Cuseo, "The Empirical Case Against Large Class Size: Adverse Effects on the Teaching, Learning, and Retention of First-Year Students," Journal of Faculty Development, vol. 21, no. 3, pp. 5-21, 2007.

[18] J. Cohen, Statistical power analysis for the behavioral sciences (2 ${ }^{\text {nd }}$ Ed.), Hillsdale, N.J.: L. Erlbaum Associates, 1988. 